\title{
El discurso humanista y latinizante de Berganza a la luz de dos episodios del Coloquio $\mathrm{y}$ de sus posibles reminiscencias
}

\author{
The Berganza's humanistic speech on two episodes of \\ the Coloquio and their Latin reminiscences' likelihood
}

Miguel Alarcos Martínez

Universidad de Oviedo

alarcosmiguel@uniovi.es

ORCID iD: https://orcid.org/0000-0002-7809-0507

RESUMEN: Lo que acotamos como un episodio diferencial del Coloquio de los perros ('el soborno de Berganza', o, al decir de Cervantes, "las dádivas de la negra"), puede investigarse desde una doble óptica, a saber: en sus aspectos generales, a propósito del discurso de Berganza y la imagen humanista que arroja, en contraste con el también posible 'humanismo' de Cipión; y, a un nivel más concreto, en relación con el usus loquendi 'berganciano', en el sentido de que tal dicción pudo haberse elaborado a partir de la influencia de autores latinos, y bajo el filtro mediatizador de las exégesis de paremiólogos renacentistas, como Polidoro Virgilio o Erasmo de Rotterdam (si bien el influjo del primero es nuestra hipótesis prioritaria), puesto que la situación episódica de 'soborno' genera la intercalación de un adagio en latín (habet bovem in lingua) que Cervantes pone en boca del can (incluso en romance: "éste tiene el buey en la lengua").

Palabras clave: El Coloquio de los perros, discurso 'berganciano', humanismo, las dádivas de la negra, el tema del 'soborno', Polidoro Virgilio, Virgilio Marón, tradición clásica, hipotextos-reminiscencias, 'inmanentismo funcionalista'.

ABSTRACT: An episode of the Coloquio de los perros, like 'the bribe of Berganza' (or, according to Cervantine sentence, "las dádivas de la negra"), could be researched for, if we mean to explore two different ways, that is, in a general sense and in its most specific aspects. Thus, such episode would show the features of Berganza's speech, which suggests a certain 'humanistic' image of himself, very different from Cipion's probably 'humanism'. In the other hand, 'Bergancian' usus loquendi would have been elaborated from various Latin influences, whose reception could be man- 
aged by Renaissance paremiologist's exegesis (for instance Polidorus or Erasmus, however our main purpose is based on Polydorian source as simply hypothesis): in fact, an adage in Latin (habet bovem in lingua) is used by the dog (even translated into Spanish language as "éste tiene el buey en la lengua").

Keywords: El Coloquio de los perros, 'bergancian' speech, humanism, las dádivas de la negra's episode, bribery's theme, Polidorus, Vergilius, Classical Tradition, hipotexts-reminiscences, 'immanent \& functional' methodology.

El coloquio de los perros (en adelante abreviado como Col.), peculiar producto de la novelística Ejemplar de Cervantes ${ }^{1}$, es probablemente el relato con mayor densidad reflexiva, intelectual y erudita de todo el conjunto. De hecho, $a$ priori se observa que el afán indagador —incluso en su vertiente más teóricacaracteriza en términos temáticos los discursos variopintos de Cipión y Berganza. No obstante, es el discurso de Berganza el que plasma con mayor nitidez la especial idiosincrasia del Col., sobre todo, si tenemos en cuenta dos de los episodios que jalonan su azarosa y peregrina trayectoria, cuya trama se corresponde con el servicio prestado en la casa de un mercader de Sevilla, y entre los que Cervantes instala una sutil trabazón estructural ${ }^{2}$.

A ambos episodios sucesivos los denominaremos 'el aprendizaje de latines por Berganza $=$ B.' (hecho prodigioso para un can, cuando asiste a los hijos del mercader en las clases de un Studium jesuita) y 'el soborno de B.' (o, si se prefiere, "las dádivas de la negra", expresión cervantina que recoge la idea básica).

En otro orden de cosas, todos los análisis realizados en el presente artículo se amoldan a una metodología y epistemología del hecho literario, cuyos rasgos distintivos estriban en los adjetivos inmanente y funcional $^{3}$.

\footnotetext{
${ }^{1}$ Seguimos la edición de H. Sieber (2014: vol. II), si bien la última ha sido la de J. García López (2015a).

${ }^{2}$ La crítica mayoritaria aborda la estructura general del Col. en función de una serie de bloques vinculados con determinadas figuras sociales, que, a su vez, se descomponen en un conjunto de 'episodios'. Así, lo que para nosotros constituyen dos unidades diferenciadas de una misma trama es para la postura hegemónica del cervantismo el episodio del 'mercader', que, junto con los del 'jifero', los 'pastores' y el 'alguacil', conformarían un primer bloque en la autobiografía berganciana, según se desprende de O. Belic (1969) y D. Mañero Lozano (2004).

${ }^{3}$ Nos referimos a las desarrolladas por E. Alarcos Llorach (1976, 1982, 1997, 2001 у 2006), personal síntesis de las ideas y principios más eficaces de diversas corrientes de estudio (preferentemente del ámbito de la ciencia del lenguaje), especialmente, la Glosemática de L. Hjelmslev (1972), junto con el Formalismo ruso y la Estilística de Dámaso Alonso: sobre estas dos últimas escuelas, vid. C. Blanco Aguinaga (1997-1998); para el origen de los adjetivos inmanente y funcional, vid. F. de Saussure (1945), creador de las nociones originales, y L. Hjelmslev (1972: 30 y 72), renovador de las mismas; o bien, para una actualización científica del 'inmanentismo funcionalista' de E. Alarcos Llorach, vid. M. Alarcos (2013: 188-189, nota $\mathrm{n}^{\circ} 1$ ). En cuanto a profundizar en el paradigma teórico y metódico 'alarquista', cfr. C. Bobes Naves (2001) o D. Villanueva Márquez (2001), así como sus posibles aplicaciones al estudio de la tradición clásica (M. Alarcos [2014a: 27-32 y 2014b]).
} 


\section{Del formato Dialógico De LA NOVEla AL Discurso De LOS CANES CERVANTINOS}

La narración autobiográfica de Berganza se inserta en un insólito engranaje dialógico, la nocturna conversación entre dos canes parlantes e ilustrados, pues Cervantes les dotó del privilegio humano del entendimiento y raciocinio, y, por si fuera poco, de una elevada cultura libresca. Todas estas características explican las convergencias discursivas de uno y otro personaje, por ejemplo, el afán reflexivo e intelectual que conlleva el tratamiento de contenidos doctos, o bien, la expresión sentenciosa y proclive a la elocuencia retórica. Asimismo, este tipo de discurso nos invita a considerar la sugerente hipótesis de una caracterización de las dos figuras perrunas como auténticos 'humanistas' de la época, un refinamiento de la imaginación cervantina que supera la invención del Lucio apuleyano ${ }^{4}$.

Pero tan inusitado diálogo pronto pasa a un segundo plano con el discurso predominante de Berganza, la diégesis de su periplo vital y desventuras; ahora bien, esta se decanta con sorprendente facilidad hacia divagaciones de todo tipo, en su mayor parte eruditas y con especial hincapié en cuestiones estéticas y éticas o incluso metafísicas (prodigios sobrenaturales y hechos maravillosos, magia, encantamientos y transformaciones), lo que supone, entre las primeras, que el egregio can pase revista a referencias onomásticas de la tradición bucólica (Col., pp. 335-338), o que se limite a reproducir lo que oyó casualmente de la plática de un poeta con un matemático o alquimista, a propósito de la Poética de Horacio (ibíd., p. 389).

Precisamente, esta insistente y frenética dinámica entre "hilo anudado" o "hilo roto" singulariza la narración autobiográfica de Berganza. Este es el recurso por el cual Cervantes no solo crea la verosimilitud de un coloquio canino, sino también confiere definitivamente a su novela un carácter dialógico tan ameno como instructivo $^{5}$. Hay que tener en cuenta que la prestigiosa estela del género literario ${ }^{6}$,

\footnotetext{
${ }^{4}$ Son varias las referencias al Asinus Aureus a lo largo del Col., como la que concierne al desenlace abierto de la novela latina (vid. p. 371). Sobre el influjo de Apuleyo, vid. F. Carrasco (1983) y A. K. Forcione (1984).

${ }^{5}$ Las características dialógicas de la novela constituyen uno de los aspectos del Col. que ha suscitado mayor interés por parte de la crítica: así, por ejemplo, en relación con aspectos narrativos, dialécticos y semiológicos, vid. J. M. Pozuelo Yvancos (1978); en cuanto a las relaciones genéricas entre autobiografía, novela y coloquio, vid. F. Sevilla Arroyo (1992); por lo que concierne al influjo del género picaresco, vid. C. Blanco Aguinaga (1957); o incluso, a propósito de los rasgos del diálogo doctrinal, de acuerdo con su praxis en el Renacimiento español, vid. L. A. Murillo (1961), así como J. Gómez (1988: en especial, 58-63; y 2006). Entre tales rasgos figura la dicotomía 'maestro/ discípulo', de la que también se ha ocupado Mañero Lozano (2004: 506).

${ }^{6}$ Aunque este es el origen del género adoptado por Cervantes, lo cierto es que el Col. constituye un crisol estilizado de otros géneros y formas literarias, no solo la picaresca: a propósito,
} 
enraizado en Platón y Cicerón ${ }^{7}$, se había diversificado ya en la Antigüedad mediante tratamientos humorísticos e imaginativos (caso de Luciano de Samósata), o bien enciclopédicos y simposiacos (Ateneo de Náucratis y Macrobio) ${ }^{8}$. Además, el género había experimentado un resurgimiento en el s. XVI con el marbete alternativo de colloquium, de la mano de literatos y polígrafos, inclusive españoles de primera magnitud ${ }^{9}$, en más de un caso influenciados por el archiconocido Colloquiorum Liber (1518) de Erasmo $^{10}$.

$\mathrm{Y}$ es que los continuos meandros bergancianos suscitan las también constantes interrupciones cipionescas, reconviniendo a su amigo o expresando diversidad de juicios y opiniones en contra o a mayor abundamiento, lo que genera a la postre el debate entre ambos. No obstante, tales rupturas de la narración no son accesorias, sino que la refuerzan con otro tipo de discurso (y otro estilo

sobre las relaciones entre diálogo y género/s literario/s, así como manipulación de fuentes heterogéneas, vid. A. Rey Hazas (1983: 119-144).

${ }^{7}$ Sobre el género del diálogo en la Antigüedad, vid. J. Andrieu (1954: 283-344), complementado con trabajos específicos sobre Platón, su concepto de 'diálogo' y su pervivencia: vid. Th. A. Szlezák (2009), A. Flórez (2011), P. Bádenas de la Peña (1984) y M. A. Candelas Colodrón (2003).

${ }^{8}$ En cuanto a los exponentes ulteriores a Platón y Cicerón, vid. F. Donadi (1989), M. C. Cabrero (2007), M. D. Gallardo (1974) y M. Alesso (2009: sin pp.). Aunque también debiera incluirse la peculiar fórmula de lo que podríamos denominar 'diálogo en diferido' (recuerdos orales, conversaciones imaginarias y dialogismo con obras previas) que nos brindan las Noches Áticas de Aulo Gelio: vid. F. García Jurado (2010 y 2012), este último trabajo sobre el llamativo sedimento geliano en el diálogo renacentista, puesto que las Noches no se tradujeron al castellano hasta el s. XIX.

${ }^{9}$ Son numerosos los cultivadores hispánicos del género del colloquium, y muy variada la temática de sus textos, tales como los hermanos Valdés (J. con su Diálogo de la lengua y A. con el suyo sobre Carón y Mercurio), El Crotalón de Cristóforo Gnofoso (diálogo o coloquio inventados por C. de Villalón), El Jardín de flores curiosas de A. de Torquemada, Fray Luis de León con De los nombres de Cristo, etc. Para más detalles, o ya para ampliar la nómina a autores estrictamente humanistas, vid. L. Gil Fernández (1997).

${ }^{10}$ Publicados por vez primera en 1518 en Basilea bajo el título de Familiarium Colloquiorum Formulae, que cambiaría en 1526 al definitivo de Familiarium Colloquiorum opus, según se infiere de la edición canónica de 1533. Ahora bien, durante la década de 1520, la colección erasmiana de diálogos gozó de un especial impacto y recepción en territorio hispánico (S. del Rey Quesada, 2013), ya que las versiones más antiguas datan del periodo 1527-1532, entre las que destaca la labor de A. de Virués (1529). En cuanto a los renacentistas españoles bajo el influjo del Colloquium erasmiano, quizá el caso más representativo lo constituya A. de Valdés y su Diálogo de Carón y Mercurio (1529), asimismo influenciado por el Carón de Luciano, que, a su vez, también dejó impronta en el homólogo Charon de Erasmo; otros autores dialogistas que pertenecen al estricto ámbito del humanismo hispánico, igualmente bajo la influencia de tal género, son J. L. Vives (F. Calero, 1994a-b, 2004a-b y 2017) y su Exercitatio Linguae Latinae (1532), y J. L. Palmireno (G. Colón Domènech, 2004: 5), creador de un diálogo imaginario entre maestro y alumno en el marco más general de su De vera \& facili imitatione Ciceronis (1560). En fin, a modo de síntesis sobre tan particular influjo de Erasmo entre los literatos y humanistas españoles, vinculados con el género áureo del diálogo, vid. M. Bataillon (1966), F. Bierlaire (1977), P. J., Donnely (1979), G. Colón Domènech (2004), T. Grigoriadu (2009), S. del Rey Quesada (2012) y F. Calero (2017: 511-512). 
literario), esto es, el parlamento reflexivo, el espacio de las sentencias y las alusiones que nos traslada hacia otra clase de conocimientos y experiencias: el discurso de las ideas sobre uno u otro aspecto de su curiosa realidad cotidiana, un discurso, pues, ostensiblemente juicioso y gnómico.

\section{Del hUMANISMO DIFERENCIAL DE BERGANZA A LAS SINGULARIDADES DE SU DISCURSO LATINIZANTE: DIVERGENCIAS COGNITIVAS CON CIPIÓN}

Así pues, la inclinación digresiva de Berganza se erige en mecanismo estructurante de la novela, sobre todo, respecto a la elaboración del personaje en todas sus facetas, por ejemplo, su idiosincrasia como ser parlante y pensante, al margen ya de sus concomitancias y/o afinidades respecto del estilo loquendi de Cipión, lo que lleva aparejado el especial carácter humanista berganciano, frente al de su interlocutor, de otra índole.

En efecto, tales divagaciones caracterizan a este perro sabio con un determinado perfil intelectual que, a nuestro juicio, difiere en calidad y cantidad del personaje más pragmático de Cipión, por cuanto el pensamiento crítico de Berganza adquiere un viso humanista mucho más selecto y erudito que el de su compañero, aun cuando este último resulta muy proclive a exégesis y aclaraciones de todo jaez; o, al menos, podría afirmarse que su capacidad para reflexionar sobre lo divino y lo humano desde la posición privilegiada de una mente cultivada es con mucho más acusada, consistente y rica en autoridades y recursos pedagógicos, en una línea que evoca sin duda los comentarios y glosas de Erasmo en cualquiera de sus escritos, o del propio Polidoro Virgilio, su rival de Urbino: por ello, Berganza se caracteriza por un cierto refinamiento o excelsitud humanistas que no deja traslucir el otro can.

No puede ser fruto de la casualidad el hecho de que, si se le compara con Cipión (oyente activo e interlocutor del diálogo), Berganza acumule mayor volumen de reminiscencias de la cultura y literatura grecorromanas, de la sabiduría popular medieval o hasta del imaginario estético y legendario del mundo cervantino contemporáneo. Por consiguiente, el más culto e ilustrado de los canes es el que tiende a apuntalar su pensamiento con el acopio de citas camufladas o sesgadas de los clásicos, no solo de la talla de autores sapienciales (por ejemplo, Cicerón, Quintiliano o Séneca), sino también de la propia novelística grecolatina. A la par, Cervantes pertrecha a Berganza con un bagaje considerable de referencias y noticias, extraídas incluso de la literatura arqueológica y miscelánea de los ss. II-V d. C., o bien, asimiladas con su lectura de creadores y preceptistas, ya mediante la fértil red de realia que atesoran los versos de su apreciadísimo Garcilaso de la Vega, ya por medio de sus admiradas Poéticas, como las de Tasso y el Pinciano. 
Ahora bien, más allá de cuantas generalidades hemos expuesto, deben examinarse dos hechos concretos que constituyen rasgos significativos de la singular caracterización intelectual de Berganza, a la vez que marcan cierta distancia rigurosa con el perfil ilustrado de Cipión, a saber: de una parte, sus esclarecidas nociones de gramática latina, latentes y decisivas en la diversidad de opiniones que plantea, a propósito de la controversia sobre el uso de "latines" en romance, localizada en el proceso episódico de 'aprendizaje de B.'; y, de otra, su sorprendente desliz respecto del significado (y segmentación etimológica) de un helenismo, ampliamente difundido en la época y de uso corriente en todo ámbito medianamente cultivado, a raíz de la utilización de tal término por el propio Cipión, en la franja de diálogo correspondiente a "las dádivas de la negra".

\subsection{Las nociones gramaticales de Berganza y su contribución a la polémica entre "latinos" y "romancistas"}

En efecto, la peculiar polémica que se suscita amistosamente entre los canes (Col.: 348-349) carecería de todo sentido y verosimilitud, en cuanto materia de un coloquio muy sui generis, si no fuera porque a ambos se les presupone un acervo común de conocimientos, lecturas y referentes culturales que les permite encauzar el diálogo hacia la discusión de ciertos temas, y, sobre todo, porque Cervantes ha atribuido a uno de ellos un mayor grado de familiaridad en el manejo de las cuestiones objeto de controversia, que no son otra cosa que la pertinencia o no del uso del latín en "las conversaciones" del romance castellano.

En otras palabras, la notoria especialización gramatical de Berganza con respecto a los "latines" justifica en el plano ficcional del diálogo la invención cervantina de una controversia, de índole filológica, que guardaba relación con los temas predilectos de los círculos eruditos de la época y exigía asimismo una comunidad de lectores, no solo medianamente o en extremo cultivados, sino también preparados en mayor o menor medida para la reflexión metalingüística, a imagen y semejanza de sus trasuntos dialógicos y perrunos.

En el presente estudio nos limitamos a acotar unas muestras selectivas de todo el conjunto, apuntando la vigencia de esta preponderancia cognitiva de Berganza sobre Cipión, en virtud de la cual se transmuta, a ojos del lector, en un humilde y pedagógico magister de gramática latina, o, si se prefiere, en el modesto ideal de latinista para Cervantes, es decir, que no desdeña un romance híbrido de latines, a la par que sabe utilizar tales giros foráneos sin excesos ni errores, con oportunidad, gracia y decoro, y con la justa y necesaria erudición.

El pasaje que cifra los comienzos de la controversia (Col., p. 348), generada a iniciativa de Berganza, presenta dos segmentaciones discursivas diferenciadas, cuyas secuencias de arranque hemos realzado con a) y b): 
a) como me estaba todo el día ocioso y la ociosidad sea madre de los pensamientos, di en repasar con la memoria algunos latines que me quedaron en ella de muchos que oí cuando fui con mis amos al estudio, con que, [...] determiné, como si hablar supiera, aprovecharme dellos en las ocasiones que se me ofreciesen; b) pero en manera diferente de la que se suelen aprovechar algunos ignorantes. Hay algunos romancistas que en las conversaciones disparan de cuando en cuando con algún latín breve y compendioso, dando a entender a los que no lo entienden que son grandes latinos, y apenas saben declinar un nombre ni conjugar un verbo.

La primera de estas segmentaciones (a) es de carácter diegético (líneas 1-4 del texto sangrado), originándose, sin embargo, su sustancia narrativa con anterioridad a la p. 348, o sea, en el ámbito de la acción del 'aprendizaje' que precisamente culmina y expira en este pasaje; en cuanto a la segunda (b), de índole digresiva, ocupa las lín. 4-7, cuya marca formal distintiva estriba en la conjunción / pero /, pues supone todo un contraste sintáctico y expresivo con las secuencias precedentes.

Comencemos el análisis con la porción textual (a), fijándonos en su punto de arranque (“di en repasar con la memoria algunos latines...”), por medio del cual Cervantes a lo menos insinúa la especial soltura de nuestro can con el latín, así como el grado de familiaridad con su gramática, en velada oposición a la figura de Cipión. Tal segmento ofrece pruebas específicas de nuestro aserto a tenor sobre todo de su selección léxica, mostrando una serie de núcleos expresivos, cuyo contenido es susceptible de sintetizarse en dos direcciones: por un lado, la alusión a las circunstancias que favorecieron el curioso y exclusivo aprendizaje de Berganza bajo influjo de un "Estudio"; y, por otro, sus prodigiosas aptitudes para emular, con la mayor espontaneidad y naturalidad posibles, los hábitos esencialmente humanos de un alumno en formación, es decir, tanto "repasar con la memoria" (o 'recordar') "algunos latines" de los "muchos que oí", como previamente asimilarlos ejercitando el sentido del oído.

Al autorretrato del perro discente y ocioso, que combate el tedio con ejercicios mnemotécnicos y latinizantes, sigue la actitud de adhesión a la lengua latina o valoración positiva de la misma, de suerte que Berganza obtiene provecho de lo aprendido, sacándole todo el jugo que le es posible: "determiné, como si hablar supiera, aprovecharme dellos en las ocasiones que se me ofreciesen". En realidad, en tal segmento hay comprimida toda una declaración cervantina de principios sobre el valor formativo y cultural del latín y, por tanto, una apología no irónica de la intercalación de citas latinas en el castellano.

Pero desde el ángulo exclusivo del personaje, la selección cervantina del verbo "determiné" plasma una concepción personal sobre la utilidad del latín en su idioma nativo, perfectamente compatible con el español actual, que se materializa en dos finalidades: de una parte, la concretísima que se vincula estrecha- 
mente con la elaboración de sus discursos, tanto en el presente episodio como en el ulterior de "las dádivas de la negra"; $y$, de otra, la que se relaciona con su inusitada propiedad del habla articulada, según se desprende de la estructura hipotética "como si hablar supiera", y que profiere como posible resultado un usus loquendi culto, entretejido con su fascinación por la lengua de Roma, así como supeditado a la expresión del pensamiento y sus múltiples formas, en fin, un estilo, no sin artificios retóricos, pero en absoluto pedante.

$\mathrm{Y}$ es que esa vertiente discursiva, docta y exquisita, que surge del enaltecimiento berganciano de los latines y sus prácticas enriquecedoras, instaura a partir de este momento la suspensión del hilo narrativo y el desarrollo de una digresión metalingüística que concatena a) con b): “[determiné]... pero en manera diferente de la que se suelen aprovechar algunos ignorantes"; tan peculiar digressio asume ya la forma reflexiva e intelectual de un juicio crítico severo, detonante de la polémica que se desata entre los personajes: Berganza, no obstante, arremete, no sin un morigerado tono, contra algunos ignorantes que propugnan cierta manera diferente respecto del uso del latín combinado con el romance, como pudiera ser a buen seguro una praxis errónea, que sin duda deja en muy buen lugar la figura de nuestro can y consolida su caracterización de perro sabio y erudito en cuestiones latinizantes, tal que si fuera un nuevo Palmireno en versión canina, un humanista, pues, de la cabeza a las pezuñas.

Ya situados en la fracción textual (b), este segmento (estructura adversativa de / pero / + un adjetivo, que abona el terreno para una probable comparación con otros sujetos), a su vez, materializa una delicada y eficaz distinción creada por Cervantes para encumbrar definitivamente el tratamiento berganciano a la categoría indiscutible de ejemplo paradigmático, constituyendo entonces su natural contrapunto el 'aprovechamiento' petulante, vacuo ( causa, en fin, 'ignorante') o infundado de algunos (denominados luego "romancistas"), así como para confirmar la idea de excelencia humanista que lo separa cualitativamente de Cipión, en cuya réplica subyacen actitudes y concepciones en torno al valor y uso del latín, diseñadas como otras 'maneras diferentes' de enfocar el asunto de la polémica, que, sin embargo, no incurrirían en las reprobables tachas de las maneras de los ignorantes.

De hecho, las 'maneras' cipionescas en el debate que nos ocupa no constituyen alternativas viciadas de 'aprovechamiento', sino tratamientos concebidos desde otros presupuestos, esto es, ligados con la apología a ultranza del romance y, por tanto, de su pretendida pureza, o, lo que es lo mismo, con la exclusión de los giros latinos, a la hora de construir todo discurso en castellano: así, mientras Berganza continúa su crítica digresión contra el modus operandi de algunos ignaros ("hay algunos romancistas que en las conversaciones disparan de cuando en cuando con algún latín breve y compendioso"), ampliándola con una argumentación más concreta y precisa ("dando a entender a los que no lo 
entienden que son grandes latinos, y apenas saben declinar un nombre ni conjugar un verbo"), por el contrario, su colega Cipión agregará que el mayor daño no estriba en los disparos de romancistas jactanciosos que se las dan de entendidos, cuando apenas saben de gramática latina ("por menor daño tengo ése...", comienza así el turno dialógico cipionesco, en clara referencia a las ideas del reproche berganciano), sino en "el que hacen los que verdaderamente saben latín", distinguiendo además a "algunos tan imprudentes que, hablando con un zapatero o con un sastre, arrojan latines como agua" (p. 348).

A la vista de las secuencias confrontadas de uno y otro can, se observan divergencias estilísticas que apuntan a la diferente construcción del discurso reflexivo e intelectual en boca de cada personaje, resultando mucho más elaborada la expresión discursiva de Berganza que la de Cipión, como se deduce del realce en cursiva aplicado a sus elementos significativos, todos ellos forjados a partir de construcciones antitéticas ('dando a entender' / 'los que no lo entienden' || 'son grandes latinos' / 'apenas saben + declinar, conjugar'); y tal sofisticación lógicamente también repercute en el plano del significado, de suerte que el discurso de Berganza, a efectos semánticos, se presenta más rico en detalles y preciso en argumentaciones (incluso especializadas en función de los conceptos gramaticales de 'declinación' y 'conjugación'), a la par que provisto de erudición y profundidad analíticas.

Por otra parte, la doble oposición semántica que enriquece la argumentación de Berganza permite fijar los rasgos 'reales' y 'aparentes' de todo romancista presuntuoso y con un grado de conocimiento de la materia indirecto o, cuando menos, vago, que ni siquiera supera los mínimos exigidos de nociones elementales (el adverbio apenas, introducido por Cervantes, puntualiza como dudoso el presunto dominio de la lengua latina, esto es, el hecho de 'saber' declinar un nombre o conjugar un verbo).

A resultas de tal organización del contenido, se deduce que esa clase de romancistas son en realidad grandes latinos farsantes, quedando asimilados, pues, a aquellos ignorantes, cuya manera diferente se contrapone a la que desarrolla Berganza "en las ocasiones que se me ofreciesen", al entreverar su dicción romance con los latines aprehendidos del Estudio jesuita; y esa ecuación berganciana 'romancistas = ignorantes', a su vez, contrasta con el discurso replicante de Cipión, por efecto de lo que constituye su natural pareja complementaria, esto es, 'latinistas = imprudentes', fruto de una atolondrada y tergiversada generalización sobre quienes hacen mayor daño en la mixtura de romance y latines.

Por lo tanto, de todo este análisis podemos inferir la evidencia de que Cervantes dispuso las divergencias intelectuales entre los caracteres del Coloquio, aun cuando los hiciera confluir en aptitudes y actitudes generales del Humanismo, vinculadas con temáticas de indagación, erudición o exégesis, y 
los representara, a fin de cuentas, con la peculiar imagen humanizada de perros cultos, pertrechados de sabiduría; y, asimismo, esas divergencias (análogamente discursivas) suponen la superioridad erudita de Berganza sobre Cipión en el específico terreno de la lengua latina, su gramática y su aplicación al romance, cuya prueba más diáfana la constituye el argumento de la ignorancia gramatical romancista ("apenas saben declinar un nombre ni conjugar un verbo"), pues, para sostener tal argumentación como razón restrictiva de peso, el personaje ha de emplear forzosamente una terminología acorde a la disciplina objeto de discusión (nombre, verbo, declinar, conjugar), por lo que debemos presumir que conoce en profundidad y discierne los conceptos morfosintácticos de 'nombre' / 'verbo', junto con las nociones englobantes de 'declinación' / ‘conjugación'.

Otra conclusión consistiría en el hecho de que el diálogo entre ambos canes pone de relieve una polémica abordada desde dos puntos de vista radicalmente opuestos: de una parte, el de Berganza, centrado en la admiración de la lengua clásica de Roma y, por tanto, en su aprovechamiento como material de calidad, cuando se habla romance; y, de otra, el de Cipión, orientado al encarecimiento de la lengua romance hispánica, sin menoscabo de su pureza, concepción toda ella de tintes negativos y prejuiciosos, que no tiene reparos incluso en ningunear el correcto uso del latín con el romance, cuando este emana de "los que saben verdaderamente hablarlo".

El inequívoco contraste de actitudes y concepciones caninas muestra a todas luces el afán no latinizante de Cipión, concretado en un escaso interés hacia la lengua del Lacio o en su indiferencia más ostensible rozando la incomprensión. Ahora bien, puede que tantos prejuicios y cuidados en contra no sean más que un preclaro síntoma de su paupérrima preparación en materia gramatical y en el arte de la traducción.

\subsection{De la imagen helenista de Cipión a la laguna cognitiva de Berganza: el caso de la digresión etimologizante sobre la voz "filosofía"}

Por lo que atañe a la segunda de las singularidades cruciales del discurso humanista y latinizante berganciano (su curiosa laguna cognitiva en lengua griega), el pasaje que seleccionamos se halla integrado en la estructura digresiva que dispone el episodio de "las dádivas", a modo de refuerzo del nudo de la trama (las 'reacciones de B. como víctima de soborno'), franja dialógica (Col. pp. 350351), articulada en torno a siete turnos alternantes de los caracteres (B. + C. + B. + C. + B. + C. + B.).

Este ejemplo resulta a priori un tanto inesperado para la caracterización de Berganza y sumamente llamativo en cuanto a las intenciones estéticas cervantinas; sin embargo, el filón más interesante estribaría en el ulterior turno de 
Cipión, pues su digresión inicial (las "buenas razones" de la 'filosofía', entre las que cuenta la sentencia de B. en torno a "los perros honrados") genera la infinita curiosidad de Berganza, esto es, su petición expresa para que le sea aclarada la exacta significación del vocablo filosofía ("primero te quiero rogar me digas, si es que lo sabes, qué quiere decir filosofía, que, aunque yo la nombro, no sé lo que es; solo me doy a entender que es cosa buena"), lo que da pie a una inusitada imagen de Cipión, la de humanista experto en etimologías griegas y en su explicatio verborum, según se colige de los siguientes turnos del diálogo reproducidos a continuación:

C. Con brevedad te lo diré. Este nombre se compone de dos nombres griegos, que son FILOS y SOFÍA: FILOS quiere decir 'amor', y SOFÍA, la 'ciencia'; así que filosofía significa 'amor de la ciencia', y filósofo, 'amador de la ciencia'.

B. Mucho sabes, Cipión. ¿Quién diablos te enseñó a ti nombres griegos? (p. $350)$.

De aquí parece deducirse que el humanismo diferencial de Berganza lo es tanto como el de Cipión, ya que ambos estarían especializados en conocimientos filológicos relacionados con las lenguas clásicas: el primero con la gramática latina (y, como luego se verá a raíz del estudio de fuentes del episodio, con el latín paremiológico); y el segundo con la lengua griega, en sus aspectos etimológicos y léxicos, $\mathrm{y}$, siempre, en estrecha relación tanto con el campo semántico de la 'filosofía' como con la disciplina en sí y sus nociones primordiales, inclusive históricas.

No obstante, la respuesta que Cipión da a Berganza, anonadado con la exégesis y los conocimientos que esta implica, quita hierro a tantas ínfulas de erudición, como nos ha hecho creer Cervantes, en uno de esos juegos malabares suyos entre fina ironía y beatífica sorna, como si se pusiera en tela de juicio la preclara preponderancia berganciana sobre los rasgos caracterizadores cipionescos:

C. Verdaderamente, Berganza, que eres simple, pues desto haces caso; porque éstas son cosas que las saben los niños de la escuela, y también hay quien presuma saber la lengua griega, sin saberla, como la latina, ignorándola (p. 350).

Si antes, a propósito de la polémica en el episodio de 'aprendizaje', el papel de simple lo encarnaba Cipión, frente a la visión más profunda y cabal de su colega, ahora Cervantes parecería invertir las tornas ("verdaderamente, Berganza, que eres simple"); mas Cipión hace gala de increíble modestia, relativizando su asombroso magisterio ("desto haces caso"), pues tales conocimientos suyos emanan de una cultura general que aprenden los niños de la es- 
cuela, lo que bien podría demostrarse en las clases de Humanidades que impartía la Compañía. En cualquier caso, la duda sobre el incógnito aprendizaje de Cipión, frente al conocido de Berganza en un studium sevillano, es lo de menos, al recordar que las figuras parlantes y con tantos afanes lingüísticos no son más que perros, que, por definición, no habrían de frecuentar las aulas escolares, ni mucho menos emular los hábitos humanos de instrucción.

El pasaje que, por lo demás, entronca con la controversia filológica de latines y romance - concretamente con su epílogo-, al señalar que también hay presuntuosos que desconocen la lengua griega y se las dan de muy duchos en semejante idioma ("hay quien presuma saber la lengua griega, sin saberla"), dibuja un panorama más completo de la difusión del griego como lengua de cultura en la España de Cervantes y, sobremanera, como materia escolar, consecuencia de la digresión sobre el concepto y significante etimológicos de 'filosofía', a cuenta del requerimiento léxico de Berganza a Cipión. Y, por ello, Cervantes distingue entre la sabiduría de los niños de la escuela, en torno a etimología y léxico de la lengua griega (conocimientos, pues, elementales y básicos, pero adquiridos desde la más tierna infancia) y la que se presupone a adultos y profesionales maduros (quien presuma saber la lengua griega), que luego resultan charlatanes, fanfarrones e ignaros (sin saberla, como la latina, ignorándola), y no mentes cultivadas y sabias, con respecto a los conocimientos que aseguran atesorar.

Por lo tanto, a la vista de la respuesta tan modesta de Cipión, y considerando todo lo expuesto en torno a este último ejemplo sobre los rasgos significativos y cruciales de Berganza, resulta claro que tan elemental (o simple) laguna berganciana no desmerece en absoluto ni eclipsa su esclarecido humanismo latinizante, ni tampoco sus otras características intelectuales y discursivas que lo encumbran a una posición privilegiada sobre Cipión y lo definen con una imagen mucho más docta, erudita, ingeniosa y sofisticada que su compañero de diálogo.

Del mismo modo, este último pasaje da pruebas inequívocas del verdadero carácter de Cipión, y de cuantas estrecheces de miras presenta su formación humanística, y sus concepciones ante temas como los relativos al uso de lenguas clásicas, o bien, a la explicación de expresiones de las mismas: no por saber Cipión lo elemental del griego que desconoce Berganza, resulta ahora más sólido y sabio que el can ducho en latines; además, si en la polémica de los latines perdía peso la figura de Cipión, en este contexto nuevo, donde parece llevar la voz cantante, cual si imitara la línea de actuación de su colega, empero, resulta mucho más anodino y simple que nunca, porque en aquello que podría destacar como singularidad propia, al margen de sus devaneos con la "filosofía" y las "murmuraciones", al final, él mismo lo invalida, degradándolo a mera instrucción infantil de la escuelas. 
Así las cosas, el pasaje sirve para valorar por separado los rasgos propios de cada uno, y para introducir índices correctores de verosimilitud o realismo, pues ambos son perros, y, además, humanados, por tanto, susceptibles de acumular defectos y cualidades, por lo que ambos canes han de presentar en sus individuales caracterizaciones lagunas cognoscitivas.

Completamos esta fase de estudio con la corroborada tesis de un humanismo y discurso diferenciales para Berganza, que pueden sintetizarse en los siguientes rasgos caracterizadores: cierta profundidad y erudición en gramática latina y, como luego veremos, también en paremiología romana, vocación pedagógica, tendencia constante a la indagación y a toda clase de digresiones, certero y comedido juicio crítico, lecturas literarias variopintas, refinado ingenio y juegos de elocuencia muy elaborados, y, sobre todo, amplitud de miras y flexibilidad, a la hora de conjugar el romance con sus latines aprendidos ("de molde", expresión cervantina en boca de B.).

Por el contrario, la imagen humanista de Cipión ${ }^{11}$ es mucho más corriente, anodina y simplona, y también muy escolar, incluso en aquello que pudiera constituir su especialización filológica, como son sus pinceladas etimologizantes y léxicas de lengua griega, aunque, si hubiera que poner de relieve algunas características definitorias, estas serían su obsesión por la filosofía como compendio de "buen entendimiento" y "buenas verdades" (en un sentido estrictamente ético) y su rechazo radical de las murmuraciones, en cuanto portadoras de falsedad y apariencias; su necesidad de síntesis y pragmatismo, a menudo cristalizadas en la elaboración de su propio discurso, y en cuantas intervenciones tiene para encauzar la voz narrativa de Berganza y evitar sus meandros reflexivos; y, muy especialmente, su exaltación purista del romance, como si este no se enriqueciera con las voces prestadas por las lenguas clásicas, como el latín.

\footnotetext{
${ }^{11}$ Nuestra concepción humanista de la imagen cipionesca contrasta con los argumentos y datos manejados por la mayor parte de los cervantistas, quienes propugnan la posible caracterización escéptica, irónica o socarrona de Cipión: vid. M. I. Miranda (1985), Mañero Lozano (2004) y J. García López (2015b). Tales rasgos caracterizadores no nos convencen en demasía. Entre todas las tesis esgrimidas, sacamos a colación una de ellas y razonamos nuestras objeciones. Así, el prólogo al Quijote conforma, a todas luces, la parodia y crítica cervantinas respecto de los excesos eruditos de la época, y, desde ese ángulo, se entendería que nuestro novelista se sirve del contrapunto Cipión/Berganza para arremeter contra los hábitos latinizantes que encarna el humanismo berganciano; pero Berganza también cuestiona el exceso petulante de latines y su uso incorrecto o presuntuoso (en la línea de Nebrija, por ejemplo: sobre la génesis y desarrollo de tal controversia, vid. L. Gil Fernández, 1997:59-83), por lo que no hay ningún motivo de peso para vincular la reduccionista ideología cipionesca con el pensamiento escéptico de Cervantes, ni para hacer de Cipión un trasunto ideal del escritor.
} 
3. DiscurSo LATINIZANTE DE B. Y ELABORACIÓN INTERTEXTUAL EN EL EPISODiO DE “LAS DÁdiVAS”: DE Virgilio MARÓN A POLIDORO Virgilio

Resta un último análisis tanto para completar la singular imagen humanista de B. y sus particularidades discursivas, especialmente por lo que se refiere a las digresiones en sus aspectos formales y funcionales, como para esclarecer el grado de complejidad y sofisticación estéticas del episodio de "las dádivas", las fuentes que pudo haber asimilado Cervantes con el objeto de elaborar mediante parámetros intertextuales tanto la temática misma del 'soborno' como la caracterización de los personajes, o bien, los rasgos del discurso berganciano, no solo tipológicos, sino también lingüísticos y estilísticos.

Pues bien, la construcción del episodio, bajo este otro punto de vista, evidencia, al menos, dos focos de emulación: por un lado, la escena esencial que se integra en el discurso narrativo de Berganza, núcleo a su vez de la estructura textual y argumental; y, por otro, la digresión en torno al proverbio habet bovem in lingua, único ejemplo de esta tipología discursiva que Cervantes inserta en una fracción diferenciada de su nudo episódico ('las reacciones de B.' ante el 'soborno'), por ser exclusivamente diegética (la narración del intento de 'conjura del can sobornado' contra los negros) y desdoblarse en dos planos 'causa-efecto' ('determinación' y 'ejecución'), entre los cuales se coloca precisamente esta peculiar digressio paremiológica ${ }^{12}$.

Definidos tales focos en términos estructurales (tipológicos y combinatorios), pasamos a su caracterización desde el estricto punto de vista de las fuentes utilizadas o manipuladas por nuestro novelista: así, en el primero de ellos, se detectan reminiscencias de una escena virgiliana de la Eneida; en cambio, el segundo presenta una mayor complejidad intertextual, susceptible de interpretarse, en consonancia con nuestras hipótesis, como la posible amalgama entre las fuentes exegéticas de Erasmo y Polidoro Virgilio, humanistas coetáneos y paremiólogos rivales ${ }^{13}$.

${ }^{12}$ El presente artículo aborda el discurso paremiológico de Cervantes — y de su alter ego perruno-, exclusivamente desde una óptica generalista y compositiva, es decir, hasta qué punto este elemento del usus loquendi berganciano contribuye a la elaboración discursiva del episodio. Por lo tanto, nuestra investigación no ha de inscribirse en el ámbito de la paremiología cervantina. Por otra parte, el componente paremiológico no deja de ser un ingrediente más de la tradición clásica que Cervantes manejó para construir tanto el episodio de "las dádivas" en sí mismo como las particularidades narrativas y reflexivas del discurso berganciano. No obstante, a mayor abundamiento, consignamos aquí lo más granado de tal especialización bibliográfica: aparte del diccionario de H. Bizzarri (2015: 71-72), vid. asimismo P. M. Vega Rodríguez (1990), M. Joly (1991) o, de nuevo, Bizzarri (2003); con respecto al uso específico de proverbios en el Quijote, vid. M. Joly (1984), M. Colombi (1989) y J. Cantera Ortiz y J. Sevilla Muñoz (2005).

13 Polidoro Virgilio de Urbino, tal vez eclipsado por la fama de Erasmo, fue, sin embargo, pionero en la divulgación y comentario de proverbios (de origen grecolatino y sacro) con su Pro- 
Ahora bien, pese a reconocer de antemano una posible contaminatio entre ambos paremiólogos, a propósito de este último foco de emulación, nos centraremos en la mayor relevancia del papel influyente de Polidoro, y no tanto en Erasmo, por ser más evidente su aportación hipotextual a Cervantes, aunque de alcance más restringido, y, sobre todo, porque el objeto de la investigación no radica en la influencia del holandés, sino en la hipótesis alternativa de un influjo polidoriano, que rebasa incluso el ámbito estrictamente paremiológico del episodio.

\subsection{La elaboración narrativa del tema del 'soborno': la escena nuclear de los "pedazos" y sus reminiscencias virgilianas}

En efecto, el primero de tales focos (“...y, tapándome la boca con algún pedazo de carne o queso, abría al negro, facilitándolo mi silencio....", Col. p. 350), del que Cervantes pergeña un eco ulterior ("...fiada en que me enmudecían los pedazos de carne, pan o queso que me arrojaba”, p. 352), constituiría un más que plausible conjunto de reminiscencias de la Eneida VI (vv. 417425), en los que la Sibila de Cumas arroja al infernal Cerbero un somnífero, en forma de 'bollo de miel y frutos tratados' ("Cui vates.../ melle soporatam et medicatis frugibus offam /obicit”), dejando así el paso franco al héroe virgiliano ("occupat Aeneas aditum custode sepulto"):
Cerberus haec ingens latratu regna trifauci personat aduerso recubans immanis in antro. Cui uates horrere uidens iam colla colubris melle soporatam et medicatis frugibus offam obicit. Ille fame rabida tria guttura pandens corripit obiectam, atque immania terga resoluit fusus humi totoque ingens extenditur antro. Occupat Aeneas aditum custode sepulto euaditque celer ripam inremeabilis undae. ${ }^{14}$

verbiorum Libellus (1498), ya que la antología de paremias del de Rotterdam se publicó por primera vez tan solo dos años después, no fijando su edición definitiva hasta 1536. La rivalidad existente entre ambos genera cierto afán diferenciador en cada una de las ediciones que fueron alumbrando respecto de sus obras: no es de extrañar que el bos in lingua de Erasmo no figure en Polidoro, y que, en cambio, este recoja otras dos expresiones con sentido similar, temática idéntica (la del 'soborno') y léxico afín al campo semántico de 'lengua' (el adagio n⿳ 479 de la serie sacra, obstruere / obturare os ['tapar la boca'] y el n ${ }^{\circ} 48$ de la serie profana, argentanginam pati ['padecer "dineroanginas"]). Para mayor información sobre Polidoro y su interacción con Erasmo, vid. A. Serrano Cueto (2002 y 2007: 9-48). Por lo que se refiere a la ejemplificación textual de estos autores en nuestro trabajo, las citas de Erasmo y referencias a su bos in lingua proceden de ejemplares digitalizados de las ed. de 1523 y 1536, si bien recomendamos la ed. moderna de M. Szymanski (2005); y para los pasajes polidorianos seguimos el texto ya traducido de Serrano Cueto (2007).

${ }^{14}$ Trad. de R. Bonifaz Nuño (2008: 129), una de las más acertadas, en cuanto a fidelidad con el texto original: "El ingente Cerbero estos reinos con trifauce ladrido / atruena, acostándose, in- 
El cotejo entre las secuencias cervantinas y los versos de Virgilio nos permite vislumbrar una serie de analogías en el plano semántico, que llevan lógicamente a consideraciones argumentales, temáticas y ficcionales. Si bien existen algunas convergencias entre vocablos ${ }^{15}$, lo cierto es que la expresión literaria de Cervantes difiere en mucho de la elaborada por el Mantuano. Por consiguiente, la emulación cervantina de Virgilio se realiza en términos estrictamente de contenido, innovándose a priori en el plano del significante, en cualquiera de sus combinaciones posibles (fónica, morfosintáctica y hasta de selección léxica).

Así pues, tanto la escena virgiliana como la cervantina presentan características comunes: de entrada, el detalle significativo de que Cerbero identifique a un personaje de condición animal, en concreto, a un perro, al igual que Berganza, además de que uno y otro conformen prodigiosos especímenes caninos, si bien los rasgos extraordinarios de tales criaturas son bien diferentes, dado que el can inventado por Cervantes, aparte de ladrar, habla, piensa, razona y entiende, como lo haría un ser humano, y, además, posee la cultura, oratoria, erudición y sapiencia de un humanista cuasi profesional.

Después, el hecho de que ambos canes tengan por antagonistas a otros dos caracteres, que, en contraste, son humanos y se alinean en forma de parejas, aunque de diversa naturaleza (la eventual amistad entre la Sibila de Cumas y Eneas, por parte de Virgilio, y, por obra de Cervantes, la fraguada en torno a un vínculo erótico, o sea, "la negra de casa" con su "negro enamorado").

Y, por último, la acción argumental que relaciona a toda esta tríada de figuras de la Eneida y del Col., es, sin duda, homogénea en sus trazos esenciales, ya que tanto Cerbero como Berganza, hambrientos en extremo, sucumben a un 'soborno' perpetrado a manos de uno de sus oponentes (la Sibila y la esclava de color, respectivamente, frente a Eneas y el amante negro de la criada, meros

menso, en el antro de enfrente. / La profetisa, al ver ya erizarse de culebras sus cuellos, / un pan soporífero de miel y trigos con drogas / le arroja. Él con hambre rabiosa, las tres gargantas abriendo, / coge lo arrojado, y las inmensas espaldas relaja, / y esparcido en el suelo, ingente, en el antro todo se extiende. / Ocupa Eneas la entrada, sepultado el custodio, / y, célere, evade de la onda sin regreso la orilla". No hay que descartar el probable influjo traductológico en Cervantes, es decir, el de versiones coetáneas de la Eneida, como la de G. Hernández de Velasco (1555), editada por V. Bejarano (2000).

${ }^{15}$ La más obvia es 'arrojar', una de las nociones esenciales en ambas escenas, expresada por los verbos obicit y me arrojaba, amén de la forma derivada obiectam, participio virgiliano; no tan evidente, por discutible, dependiendo de la opción traductológica que se adopte, es el caso de la posible correspondencia entre la forma latina offam y dos construcciones sintagmáticas de Cervantes, esto es, algún pedazo (de 'ciertos manjares') y los pedazos de pan, pues OFFA tiene por significado primario, precisamente, el de 'trozo', sobre todo, de 'alimentos, viandas', y, por ende, el de 'bocado' (cfr. Plauto, Miles gloriosus, 3, 1, 165: ...ofam porcinam...), aunque entre sus acepciones figuradas también tenemos la de 'pequeña bola hecha de harina' (cfr. Festo, 242), que conlleva, a su vez, las significaciones metonímicas de 'bollo, torta, pan' (incluso 'buñuelo' y 'albóndiga'). 
comparsas contemplativos), acto este, si no idéntico, al menos análogo, no solo por su modus operandi (dádivas 'alimenticias y comestibles', y 'arrojadas' además en 'trozos', según sugiere el vocablo virgiliano OFFA, o bien, a modo de pedazos, con arreglo al léxico cervantino), sino también por su doble finalidad, es decir, 'silenciar' los ladridos, en tanto que ambos perros vigilan el acceso a umbrales restringidos, y 'dejar el paso franco a intrusos' (en un caso, a Eneas, al querer traspasar cierto recinto recóndito del Hades, en pos de un preciado ramo de oro, y, en el otro, al mismísimo negro sin nombre, al que "abría la negra" para "refocilarse" con él "todas las noches", "...facilitándolo mi silencio", según el testimonio berganciano).

Ahora bien, la configuración cervantina de tal situación ficcional de "las dádivas de la negra" ( $\mathrm{y}$, por extensión, del tema del 'soborno'), arroja, en comparación con los hipotextos virgilianos (destacados en cursiva en el texto sangrado), relevantes divergencias de planteamiento, no solo las más obvias, derivadas de las dispares exigencias argumentales de cada obra, sino también aquellas llamativas que sí pretendemos dilucidar, vinculadas con una de las convergencias aducidas entre Cervantes y Virgilio: la entidad imaginaria del 'soborno comestible' y sus efectos expresivos.

Por lo pronto, los dadivosos 'manjares' arrojados a nuestros dos canes no pertenecen a la misma clase de 'vianda', pues lo que acalla el 'ladrido trifauce' (latratu trifauce) de Cerbero es un 'bollo / pan', compuesto por 2 elemento heterogéneos, 'de miel y frutos tratados' ("melle soporatam et medicatis frugibus offam"), mientras que, en el caso berganciano, se trata, en conjunto, de pedazos de distintos alimentos, que hacen un total de 3 (o sea, carne, queso y pan), por lo que nuestro novelista habría reelaborado el cebo comestible de las 'dádivas' virgilianas con arreglo a una serie de estrategias combinadas de simplificación, y diversificación hiperbólicas, en uno de esos giros tan característicos de su estética manierista.

De aquí que, en resumidas cuentas, Berganza se lleve al buche tres 'manjares' diferenciados, y a la vez caracterizados por su composición homogénea o indistinta, frente al único 'bocado' de que dispone Virgilio. En contraste, este último resulta mucho más elaborado, contundente y goloso que los frugales, salados y humildes de las 'dádivas' cervantinas, pues Cerbero puede degustar en un solo 'manjar' hasta, al menos, tres distintos, con sus respectivos sabores (la masa de 'harina' o 'pan', el dulzor de la 'miel' y el encanto añadido de unos 'frutos' manipulados).

Conforme a tales innovaciones semánticas, se ejecuta la reelaboración cervantina del texto-origen, lo que supone también redefinir uno de los aspectos fundamentales de la ficción virgiliana del 'soborno comestible', esto es, la entidad imaginaria del 'manjar arrojado', por lo que Cervantes constituye su especial contrapunto. 
Sin embargo, a efectos del dialogismo intertextual con la Eneida, se trataría de una suerte de quiasmo, como se infiere del esquema que sigue (V. y C. son abreviaturas de los autores cotejados):

V. > 1 'manjar' (composición heterogénea): incluye 3 'manjares'

['bollo / pan']

C. $>3$ 'manjares' (composición homogénea): incluye 1 'manjar'

['masa de harina'/'pan', 'miel' y 'frutos']

['queso', 'carne' y 'pan']

[el 'queso/carne/pan y sus ingredientes']

Por lo tanto, el v. 420 virgiliano pudo influir, en cuanto contenido hipotextual, en dos segmentos simétricos y enfáticos ("...algún pedazo de carne o queso...", p. 350 y "...los pedazos de carne, pan o queso...", p. 352), integrantes del pasaje nuclear del episodio, por lo que dichos segmentos funcionan como reminiscencias cervantinas de Virgilio, no solo a nivel textual, sino a efectos ficcionales y temáticos.

Sin embargo, eso no es todo, por lo que concierne al planteamiento virgiliano de "las dádivas de la negra", conceptualizadas estas únicamente en su condición imaginaria de 'objeto comestible' (o 'manjar'), símbolo de la ficción del 'soborno alimenticio'; queda, pues, por aquilatar otro componente, es decir, sus efectos expresivos, de acuerdo con el planteamiento de Cervantes y desde la perspectiva de su reelaboración de Virgilio, incluso en el plano de los significantes lexemáticos.

En efecto, bien que volvamos la vista a las secuencias anteriores (Eneida, 6, v. 420), se advierte que las 'dádivas' ideadas por Virgilio arrastran un rasgo imaginario no mencionado hasta ahora, cuyos valores expresivos resultan especialmente reveladores en comparación con Cervantes, puesto que no se consigna en los pedazos distribuidos por la negra a Berganza, a saber: el 'bollo' como 'somnífero' o narcótico, tal como se colige del participio SOPORATA ('soporífera', noción en género femenino, en concordancia con el sustantivo OFFA, al que califica), así como de los vv. 422-23, plástica descripción de la laxitud que invade paulatinamente la inmensidad corporal del guardián, hasta su total 'silenciamiento' onírico, según se infiere del culminante ablativo absoluto custode sepulto, a su vez, antítesis de la dinámica estructura "occupat Aeneas aditum" (todos ellos constituyentes sintagmáticos del v. 424).

Por tanto, el planteamiento ficcional del 'soborno' en Virgilio es mucho más complejo que en Cervantes, quien ha efectuado una deliberada reducción del mismo, adueñándose tan solo de la idea de los 'manjares por dádivas' y, en consecuencia, renunciando al rasgo del 'manjar-somnífero' que conlleva un eficiente modus operandi para lograr el 'silencio' duradero en su criatura canina. En otro orden de cosas, la reelaboración cervantina del v. 420 no solo evidencia una acusada reminiscencia virgiliana en la elaboración de la escena nuclear del episodio, sino también una prueba textual significativa sobre la validez de 
nuestra hipótesis intertextual en relación con el núcleo episódico y sus posibles emulaciones.

Finalmente, hay que reparar en los efectos expresivos que cada concepción ficcional del 'soborno' ha originado o, mejor dicho, en aquellos que el propio Cervantes ha desplegado en virtud de la supresión del valor virgiliano del 'manjar-somnífero'.

En primer lugar, si Virgilio encarna un concepto de 'dádivas' muy imaginativo, o bien una imagen polisémica del 'soborno' (rica en lecturas metafóricas y valores simbólicos), en concordancia con el perfil mitológico y fantástico de Cerbero y con el especial marco estético del género de la épica greco-romana, en cambio, Cervantes, como consecuencia de su reelaboración reduccionista, elabora una versión mucho más verosímil, con una expresividad menos artificiosa y figurada, tanto de acuerdo con la ambientación costumbrista y picaresca de su novela como por exigencias de la evolución argumental de Berganza, compatibles todos ellos con la idea virgiliana de los 'manjares por dádivas'. Tal rasgo constructivo está en íntima correlación con aspectos cotidianos del realismo autobiográfico berganciano (su caída en desgracia, el hambre que lo devora, su propia supervivencia ante el tratamiento vejatorio de los negros).

Además, hay otros criterios estéticos que han condicionado la reelaboración cervantina, es decir, aquellos que definen su especial caracterización humanizada e intelectual y que, por ello, estimulan en el can 'sobornado' las reflexiones inteligentes y eruditas sobre tal vivencia, sus dudas entre la necesidad de manutención y la lealtad al amo, la rectificación de su 'silenciamiento' y las reacciones de su honradez y dignidad, materializadas en su 'conjura' (ataques "a la sorda" y, luego, ladridos no acallados) contra sus mezquinos y dadivosos cuidadores, que, malograda, se salda con su retirada voluntaria y sigilosa de la casa del mercader.

En segundo y último lugar, tanto Virgilio como Cervantes configuran diversos grados de 'silenciamiento' de sus respectivos perros: así, el poeta latino se sirve del subterfugio artificioso y falaz del 'manjar-somnífero' para sumir a Cerbero en profundo sueño, es decir, para 'enmudecer' sus ladridos de forma efectiva y eficaz, aunque no permanente (según dure el tránsito de Eneas), mientras que nuestro novelista recurre a los pedazos de carne, queso y pan (sin efecto alguno de somnolencia ni ambages encubiertos) para saciar así su apetito voraz, desviando la atención de centinela hacia nutritivos menesteres que le mantienen ocupada la boca, es decir, para también 'enmudecer' sus ladridos de forma eficaz durante las noches (mientras se repitan los furtivos encuentros de los esclavos).

Y de ahí que, en el caso del can virgiliano, su 'silencio' sea absoluto, aunque involuntario e inadvertido, lo propio de quien se queda súbitamente dormido, un 'silencio' además objetivo y real (en la acepción más literal del térmi- 
no), frente al parcial e inicialmente cómplice del perro cervantino, en definitiva, un 'silencio' subjetivo e interesado, así como susceptible de ser dosificado por el propio sujeto, y, en suma, peyorativo y censurable, arraigado en los valores figurados del vocablo.

Por lo tanto, el resultado de las reelaboraciones cervantinas (los valores expresivos de la ficción del 'soborno') apunta también hacia el funcionamiento de reminiscencias contrastivas que marcan la creación por parte de Cervantes de antítesis con respecto a las soluciones formalizadas por los hipotextos virgilianos considerados o aludidos, esto es, prioritariamente, el v. 420, y, en menor medida, los vv. 422-24; e incluso, como ya sucedió con la tipología de las 'dádivas comestibles' o 'manjares', Cervantes dialoga con la Eneida, entrecruzando sus contrapuntos semánticos con las categorías virgilianas de contenido hipotextual, de suerte que ejecuta un nuevo y contundente quiasmo, como se desprende de este esquema:

V. > Sentido figurado del 'soborno' (< expresividad recargada) + 'silenciamiento' literal del can [Concepto imaginativo 'dádivas' > 'manjar-somnífero'] ['total', 'involuntario']

C. > Sentido literal del 'soborno' (< expresividad no artificiosa) + 'silenciamiento' figurado...

[Concepto verosímil 'dádivas' > 'manjar-dádivas'] ['bucal/vocal', 'consentido']

En conclusión, el foco de emulación virgiliana del episodio de "las dádivas de la negra", localizado en el núcleo estructural del mismo y conformado mediante su escena prototípica de 'soborno comestible'(a base de una tríada de 'manjares': carne, queso y pan, en pedazos), constituye un conjunto amplio de reminiscencias de contenido, en su mayor parte, supeditadas a determinados parámetros textuales, así como a criterios de elaboración temática e imaginativa, producto de la reelaboración cervantina de un entramado hipotextual de la Eneida (6, vv. 417-425), siendo el más influyente el v. 420 , en que cobra especial relevancia la figura del can Cerbero, obstáculo al paso de Eneas, y, por ello, 'silenciado' mediante la acción furtiva de unas 'dádivas-manjares' soporíferas, sin que el personaje sea consciente ni del 'soborno' aparente, ni de las verdaderas intenciones de la Sibila de aletargarlo por un tiempo.

No obstante, la selección cervantina de Virgilio como ingrediente intertextual del núcleo episódico obedece a una serie de intencionalidades estéticas, esto es, 'funciones estructurantes y descodificadoras' (M. Alarcos, 2014a: 31, 3-5) que adquieren las reminiscencias virgilianas.

Así, empezando por las primeras, los materiales reelaborados de Virgilio e incorporados al texto cervantino entrañan un valor funcional estructurante, orientados en varias direcciones: de un lado, fundamentan tanto la escena de las dádivas como la conducta de la negra y Berganza, categorías ambas de contenido influenciadas por los criterios semánticos hipotextuales y las innovaciones 
de Cervantes de este calibre; y, de otro, contribuyen a moldear la idea de 'soborno' como tema y núcleo del episodio, de acuerdo a sus propias pautas constructivas, derivadas de su particular idiosincrasia poética, puesto que Virgilio enriquece la ficción del 'soborno comestible' con el concepto imaginativo y onírico del 'manjar-somnífero', pero incluso también, según su distribución en el discurso berganciano, ya que nuestro escritor planifica una versión narrativaficcional de las dádivas.

Por lo que se refiere a la funcionalidad descodificadora del ingrediente virgiliano en el exclusivo ámbito del núcleo del episodio, esta ha de relacionarse con la caracterización de los tres personajes involucrados en la acción del 'soborno' y los juegos de reconocimiento que Cervantes impulsa en el lector, suscitando la interpretación de sus figuras a la luz de paralelismos y contrapuntos con la también tríada de caracteres fraguados por Virgilio.

Efectivamente, las mínimas confluencias entre los canes virgiliano y cervantino, y sus diferencias de diseño más numerosas y ostensibles, llevan a descodificar a Berganza, de una parte, como el contrapunto benigno y honrado del tenebroso y feroz Cerbero, y, de otra, como la sublimación reparadora o redentora del mito infernal, ya que ambos perros pasan por una análoga experiencia de 'soborno', condicionados por sus necesidades de supervivencia, si bien el caso berganciano constituye toda una conducta paradójica, en continua evolución (del dejarse 'sobornar' al arrepentimiento y recuperación de la dignidad), todo un ejemplo diáfano y realista de esfuerzo y superación que no guarda paralelismo con el fiero centinela (puro instinto, pura naturaleza animal, sin rasgo humano alguno); antes bien, esta criatura canina de ultratumba, pese a su fulgor mitológico y fabuloso, no llega siquiera a ser un pálido reflejo del prodigio humilde que es Berganza, erigiéndose, pues, en su correlato negativo más nefasto, por limitado, inconsciente y atolondrado.

De la misma manera, la caracterización de la pareja de negros se deconstruye mediante una riqueza de lecturas y perspectivas, que remiten a unos modelos contrapuestos e imaginados por Virgilio: así, la negra supone el contrapunto moral y ético de su correlato argumental en la escena virgiliana, esto es, la Sibila de Cumas, quien arroja el bollo soporífero a Cerbero, a lo que habría que añadirse el hecho de que su oscura pigmentación de piel adquiera un valor simbólico en oposición al carácter sagrado y apolíneo de la profetisa, asociada lógicamente con una imagen luminosa; y lo mismo cabe decir de la comitiva masculina, pues el negro se descodifica como potente y pasiva antítesis de Eneas, siempre pío y virtuoso, que, sin embargo, durante el periplo por el Hades, se ve eclipsado por la presencia carismática de la Sibila, quedando reducido a un segundo plano puramente contemplativo y desdibujado. 
3.2. La elaboración digresiva y paremiológica del tema del 'soborno': el adagio "habet bovem in lingua" y su valor ficcional a la luz de Polidoro

El segundo foco de emulación, objeto de análisis, arranca con el pasaje (a), "acuérdome que cuando estudiaba oí decir al preceptor un refrán latino, que ellos llaman adagio, que decía: habet bovem in lingua" (Col. p. 352), tras "determinar' Berganza conjurarse contra "la insolencia, ladronicio y deshonestidad de los negros" (ibíd.), e inmediatamente justo después de evocar la rutina nocturna y furtiva de la negra, "fiada en que me enmudecían los pedazos de carne, pan o queso que me arrojaba", lo que le hace proferir la máxima "¡Mucho pueden las dádivas, Cipión!”.

Esta última expresión cervantina constituye el punto de inflexión del discurso narrativo berganciano y, por ello, la natural transición al discurso reflexivo, que genera toda la digresión sobre el proverbio, ampliada con la propia dialéctica del diálogo entre los canes, en la que Cipión asume el papel ostensible de perplejo 'discípulo', no sin antes exhortar a su compañero "no te diviertas; pasa adelante", o incluso protestar por la intercalación de latines, fiel entonces a las posiciones de su humanismo hiper-romancista.

El contraste entre caracteres, esto es, entre la ingenuidad casi pueril de Cipión y la salida airosa o sorpresiva de Berganza, se incrementa, cuando este último puntualiza su utilización del latinajo proverbial, según se desprende del pasaje (b):

Este latín viene aquí de molde, que has de saber que los atenienses usaban, entre otras, de una moneda sellada con la figura de un buey, y, cuando algún juez dejaba de decir o hacer lo que era razón y justicia, por estar cohechado, decían: "éste tiene el buey en la lengua" (p. 352),

para luego, anonadado Cipión con "la aplicación", descender al exemplum concreto ("¿No está bien clara, si las dádivas de la negra me tuvieron muchos días mudo, que ni quería ni osaba ladrarla cuando bajaba a verse con su negro enamorado?"), reforzando Berganza su pregunta con la reiteración de la máxima de las dádivas, que, a su vez, pone punto y final a todo este desarrollo digresivo sobre el 'soborno', en una calculada dispositio circular por parte de Cervantes.

A juzgar por el segmento (b), caracterizado por el discurso exegético y paremiológico de Berganza, así como por el trasvase del refrán al español, resulta un hecho indudable los especiales parámetros con que Cervantes diseñó la caracterización discursiva e intelectual berganciana, es decir, la de un humanista de notable erudición y vocación pedagógica, al que nada de los latines le es ajeno. La erudición en el ámbito de las paremias (y en el caso de la forma habet bovem in lingua) se percibe en la propia explicación de la metonimia 'buey = moneda', pues esta se interpreta a tenor de ciertas noticias arqueológi- 
cas en torno a los presuntos usos numismáticos de Atenas como a propósito de tendencias idiomáticas, motivadas por el fenómeno de los 'sobornos' al estamento de la judicatura.

De hecho, para elaborar este afán erudito berganciano, Cervantes no tuvo que inventar ficción alguna, sino decantarse por una forma paremiológica, no desconocida en la época, que había generado a lo largo de los siglos II-XV su propio modelo explicativo, consecuencia de un bagaje filológico previo, de origen tardo-helenístico y bizantino ${ }^{16}$, aunque la expresión que más bien se generalizó no fue la que transmite El Coloquio de los perros, sino la que consigna el adagio I, 7, 18 de Erasmo (bos in lingua), a su vez, traducción del proverbio

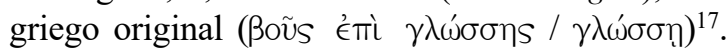

Es más, la presunta génesis numismática de la metonimia, así como el sentido proverbial vinculado con el tema del 'soborno' (aspectos de la exégesis de B.) no son otra cosa que elementos procedentes de ese paradigma de explicaciones perpetuado por las fuentes hermenéuticas en torno al proverbio helénico, si bien su influjo en la cultura occidental renacentista y, en particular, en la cultura libresca cervantina, se materializó en la mediación ejercida por la labor difusora, compiladora y pedagógica del humanismo europeo. Sin embargo, si ha de definirse el origen primario de la interpretación cervantina, este sin duda se remonta a las informaciones y conjeturas de los paremiógrafos y lexicógrafos antiguos $^{18}, \mathrm{y}$, sobre todo, a uno de los dos planteamientos exegéticos posibles, esto

${ }^{16}$ A lo largo del periodo indicado, se desarrolla toda una tradición interpretativa sobre el origen y valor semánticos del proverbio griego, consistente tanto en colecciones paremiológicas como en lexicones y repertorios enciclopédicos que atestiguan y comentan el refrán en cuestión: así, de una parte, cfr. Zenobio (II, 70, apud Leutsch \& Schneidewin, 1965: 51, vol. I) y Diogeniano (III, 48, apud L. \& Sch., 1965: 223, vol. I), ambos del s. II d. C., y, de otra, cfr. Gregorio Cyprius (I, 95, apud L. \& Sch., 1965: 358, vol. I), del s. XIII, junto con los del s. XV, o sea, Macario (II, 88, apud L. \& Sch., 1965: 152, vol. II) y Miguel Apostolio (V, 7, apud L. \& Sch., 1965: 332, vol. II); y, en cuanto a lexicógrafos y enciclopedistas, cfr. Hesiquio (entrada $\mathrm{n}^{\circ}$ 68, apud Latte, 1953: 340, vol. I), convencionalmente adscrito al s. V d. C., junto con la Suidas (entrada $\mathrm{n}^{\circ} 460$, apud Adler, 1971: 488, vol. I), del s. X, y el Etymologicum Magnum (nº 44, apud Gaisford, 1848: 320), de los ss. XII-XIII.

17 Esta notable divergencia, sin embargo, sería objeto de otra investigación, puesto que nos desvía del asunto central de nuestro análisis en esta franja del presente trabajo: tan solo apuntamos el hecho separativo de que Cervantes selecciona una forma proverbial que difiere de la seleccionada y comentada por el humanista holandés entre sus Adagia.

${ }^{18} \mathrm{El}$ proverbio que origina bos in lingua y su derivación cervantina no se constatan en otros exponentes de la tradición filológica tardo-helenística y bizantina que se vinculan con lexicones enciclopédicos no menos importantes, o que incluso han editado L. \& Sch. (1965) por su perfil de paremiólogos: así, Focio (s. IX) constituye una preclara excepción entre los eruditos bizantinos

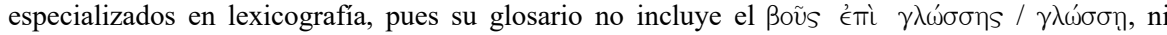
siquiera registra como lema léxico el sustantivo ßoũs (apud Theodoridis, 1982: 341-342, vol. I); por lo que atañe a paremiógrafos que no testimonien el susodicho refrán, cfr. Mantissa (I, 36, apud L. \& Sch., 1965: 749, vol. II), del s. I d. C., y Esopo (L. \& Sch., 1965: 228-230, vol. II), del s. V a. C. (el más temprano del corpus, por tanto). 
es, la línea que parte de Diogeniano y culmina en Apostolio, pues el primero de ellos introduce la noción de ‘soborno' en la discusión y reconstrucción semánticas de la paremia metonímica ${ }^{19}$.

No obstante, nuestro novelista también innova en el sentido que fijaran las concepciones hegemónicas de Zenobio y Diogeniano: en efecto, Cervantes crea una doble aplicación judicial ("cuando algún juez dejaba de decir o hacer lo que era razón y justicia") ${ }^{20}$, y, sobre todo, introduce como víctimas del "cohecho' el colectivo de los jueces, en absoluto estipulado ni manejado por los paremiógrafos y lexicógrafos antiguos, a no ser que Cervantes reinterpretara, con arreglo a algún cauce de recepción mediatizada ${ }^{21}$, la figura de los 'oradores' bajo 'soborno' que emplea Apostolio ${ }^{22}$, diferenciándose en este punto de sus

${ }^{19}$ A partir de las fuentes paremiológicas y lexicográficas en torno al proverbio aducidas con anterioridad, puede abstraerse determinada estructuración tripartita, que se refleja con divergencias en la exégesis erasmiana, e incluso aún en la urdida por Cervantes: a) definición semántica, casi siempre la misma fórmula ('con respecto a los que no pueden hablar con libertad /con franqueza'); b) interpretaciones sobre el origen del sentido figurado, 2 en concreto (o se glosan características físicas del 'animal', o bien, se reconoce una metonimia entre 'buey' y 'moneda', justificada por la presunta existencia de monedas atenienses que llevaban una imagen grabada de 'buey'); y c) apostilla, coda explicativa o inferencia secundaria de tal justificación numismática, punto en el cual se produce la divergencia de concepciones entre Zenobio y Diogeniano, y, por tanto, la reinterpretación más verosímil y razonable de este último en torno al sentido metonímico, generándose, en consecuencia, dos planteamientos contrapuestos (Diogen. > Macario y Miguel Apostolio, entre otros / Zen. > Hes. y Suid.), aunque dicho concepto experimentará cambios en la propia tradición diogeniana con la particular exégesis del último de sus eslabones, M. Apost. Aportamos algunas referencias bibliográficas de interés: para los casos de Zen. y Diogen., vid. E. Lelli, et alii. (2006); y para la pervivencia de los refranes, de origen grecolatino, vid. F. García Romero (2009).

${ }^{20}$ Sin duda Cervantes ha realizado su propia reinterpretación subjetiva del sentido proverbial: del "no decir" (o 'callar') colige la 'inacción' o 'pasividad', o sea, "el no hacer lo que era razón y justicia".

${ }^{21}$ El humanista holandés A. Schottus (1552-1629), quien ya había traducido al latín en 1606 la Bibliotheca de Focio (y en 1611 la reditaría con notas o escolios), hizo otro tanto de lo mismo con una selección de paremiógrafos griegos, al publicar su Paroimiai Hellçnikai. Adagia sive proverbia Graecorum ex Zenobio seu Zenodoto, Diogeniano \& Suidae collectaneis (Amberes, 1612). Por consiguiente, esta versión de Schottus bien podría haber facilitado a Cervantes su contacto con las paremias en lengua griega, o, cuando menos, cierto conocimiento pedagógico o idea general de las mismas.

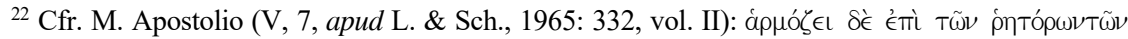

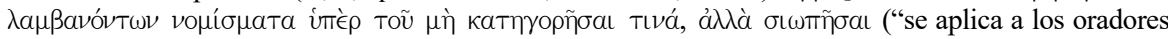
que cogían para sí mismos dinero, por el hecho, no de haber delatado a nadie, sino más bien de haberse callado"). Además de esta especificación novedosa del sujeto 'sobornado', Apostolio, a nuestro modo de ver, inaugura en la tradición paremiológica otro concepto de 'soborno' (el de 'instrumento' o 'método'), muy distinto del 'causal' (o el 'soborno' como 'causa' del 'silencio forzoso' del sujeto), el generalizado hasta entonces desde Diogeniano. Ahora bien, la configuración narrativa y ficcional de las dádivas, al discurrir por cauces virgilianos, entraña una concepción diferente de la 'causal' que prevalece en el ámbito digresivo del episodio, lo que también explicaría el hecho de que Polidoro, en la exégesis de su refrán similar obturare os, recurra a Virgilio, cuyo concepto de 'dádivas' expresa idea de 'medio' o 'método'. No puede ser, por tanto, 
predecesores, o bien, que se dejara influir por la deriva judicial del verbo 'cohechar'23.

Por consiguiente, la exégesis cervantina con toda esta tradición léxico-paremiológica helénica arrojaría diferencias de relieve, y, sobre todo, descartaría que Cervantes se inspirara en esas fuentes, por lo que los hipotextos de esta peculiar índole deberían ser las colecciones de adagios de los humanistas Polidoro y Erasmo.

Por el contrario, un cotejo específico entre Cervantes y el adagio $\mathrm{n}^{\mathrm{o}} 18$ (Chilíada I, Centuria VII) de Erasmo esclarecería especialmente la procedencia de las noticias eruditas manejadas por Berganza, definiendo la filiación de la exégesis del can, así como justificaría la forma menos escueta de la paremia cervantina.

Pero ello no es más que objetivo colateral y secundario del presente trabajo; averiguar lo fácil y evidente no nos entusiasma, sino que nos interesa aventurar hipótesis alternativas, aunque no dispongamos al día de hoy de datos suficientes para sostener con certeza tal influjo. En ese sentido, cobra fuerza la posibilidad de que Cervantes matizara lo aprehendido en Erasmo con alguna que otra lectura de aquellos proverbios polidorianos, adscritos a la temática del 'soborno', cuya aplicación expresiva pudo orientar a nuestro novelista a la hora de forjar el valor ficcional de su paremia.

Entre los casos registrados por este último, destaca el $\mathrm{n}^{\circ} 479$, esto es, $o b s$ truere os ('tapar la boca'), que registra su propia variante (obturare os), cuya significación sería la de "'corromper' a alguien con dádivas para que calle y no ofenda" (ed. Serrano Cueto, 2002: 409), lo que no deja de evocarnos el episodio cervantino y toda la sapiencia demostrada a este tenor por el paremiólogo Berganza. Más interesante, si cabe, es cómo el humanista glosa y fundamenta este significado y uso proverbiales, cuando baraja anécdotas emblemáticas de la Antigüedad que ya ha esgrimido como exégesis clasicista de otros adagios, y a un tiempo sugiere fuentes literarias virgilianas, como podemos apreciar en este pasaje (pp. 409-410):

casual todo este conjunto de conexiones conceptuales en torno a lo que denominamos 'soborno instrumental', conexiones que permiten establecer pujantes nexos entre Cervantes, Polidoro, M. Apostolio y el autor de la Eneida.

${ }^{23}$ Al igual que 'sobornar', tampoco 'cohechar' se encuentra en Covarrubias, siendo curiosamente el término que empleara Cervantes en el Col.; aun así, el DRAE esclarece la especificidad tan peculiar del verbo: de su significado primario, de índole agrícola ('alzar el barbecho o dar a la tierra la última vuelta antes de sembrar'), surge el figurado, esto es, un sentido peyorativo, aplicado exclusivamente al ámbito judicial ("sobornar, corromper con dádivas al juez, a una persona que intervenga en el juicio o a cualquier funcionario público, para que, contra justicia o derecho, haga o deje de hacer lo que se le pide"). Precisamente, los elementos realzados en cursiva parecen entroncar con las palabras de B. ("cuando algún juez dejaba de decir o hacer lo que era razón y justicia"); y es en esa analogía donde puede medirse la distancia que separa al modelo de su emulador, que no escatima en innovaciones ni en reinterpretaciones. 
Así Demóstenes, corrompido antaño por dinero, no quiso hablar contra los milesios, según expliqué en el proverbio "padecer "dinero-anginas"”; así en los infiernos Cerbero es apartado para que no dañe a Eneas, según canta el poeta....

Polidoro Virgilio, pues, recurre al poeta latino Virgilio como auctoritas en su explicación del proverbio, aduciendo precisamente los vv. 417-425 de la Eneida, 6 , cuyas reminiscencias en la escena nuclear del episodio ya hemos dilucidado.

Por lo tanto, nos preguntamos si acaso la estructura "tapándome la boca" en el pasaje narrativo de Berganza bajo influencia virgiliana no sería una reminiscencia paremiológica y exegética del obturare os polidoriano. No puede haber tanta casualidad ni afinidad de rasgos formales entre el adagio y la expresión cervantina. Ello constituye un argumento probatorio para realzar la importancia hipotextual de Polidoro en el episodio, no solo en el discurso berganciano que le resulta más familiar, sino también en el diegético, adquiriendo este humanista (frente a Erasmo) una incidencia holística.

A modo de conclusión de todo el trabajo, los episodios seleccionados (y, sobre todo, el de "las dádivas de la negra") permiten redescubrir el concepto de un humanismo graduado, en función de la caracterización discursiva de los dos canes, y, en particular, incidir en el ideal modesto y realista de 'sabio' que encarna Berganza con su erudición latinizante y pedagógica. Por otra parte, las fuentes del episodio (la obvia de Virgilio y la factible de Polidoro frente a la probable de Erasmo) fundamentan el componente latinizante del discurso humanista berganciano, y, a su vez, indican la voluntad cervantina de crear una novela intelectual, o sea, una propuesta estética que prefigura el reto más ambicioso y póstumo del Persiles, cuya publicación inminente, por lo demás, anunciaba Cervantes con ostensible urgencia en el Prólogo mismo a sus Novelas Ejemplares.

\section{BIBLIOGRAFÍA}

Alarcos Llorach, Emilio (1976): Ensayos y Estudios Literarios, Madrid, Júcar.

Alarcos Llorach, Emilio (1982): Anatomía de la “Lucha por la vida”, Madrid, Castalia.

Alarcos Llorach, Emilio (1997): Blas de Otero, Oviedo, Nobel.

Alarcos Llorach, Emilio (2001): Notas a la Regenta y otros estudios clarinianos, ed. J. L. García Martín, Oviedo, Nobel-Cátedra E. Alarcos Llorach.

Alarcos Llorach, Emilio (2006): El fruto cierto: Estudios sobre las Odas Luisianas, ed. E. Martínez Mata y pról. A. Blecua, Madrid, Cátedra.

Alarcos Martínez, Miguel (2013): "De la formación virgiliana de Cervantes a la recepción cervantina de Virgilio: problemática y cuestiones de método, a propósito del Persiles”, Revista de Estudios Latinos, XIII, pp. 187-200;

Alarcos Martínez, Miguel (2014a): Virgilio y su reelaboración cervantina en el Persiles: hacia una aproximación inmanente, Vigo, Editorial Academia del Hispanismo. 
Alarcos Martínez, Miguel (2014b): Las convenciones del género greco-bizantino y el ideal heroico de hermosura en el Persiles: hacia el sentido último de la novela, Vigo, Editorial Academia del Hispanismo.

Alesso, Marta (2009): "El género simposiaco desde Platón al cristianismo", Praesentia, X.

Alonso Hernández, José Luis (1986): ed. Teatro Universal de Proverbios (Sebastián de Horozco), Salamanca, Universidad de Salamanca.

Andrieu, Jacquelin (1954): Le dialogue antique. Structure et présentation, París, Les BellesLettres.

Apuleyo (1989): El Asno de Oro, traducido por D. López de Cortejana (1513 [publicado un siglo después]), ed. C. García Gual, Madrid, Alianza Editorial.

Apuleyo (2001): El Asno de Oro, trad. L. Rubio Fernández e introd. F. Pejenaute Rubio, Madrid, Gredos.

Arellano, Ignacio y Rafael Zafra (eds.) (2005) [1611]: Tesoro de la lengua castellana o española, Sebastián de Covarrubias, Madrid/Frankfurt, Iberoamericana/Vervuert.

Bádenas de la Peña, Pedro (1984): La estructura del diálogo platónico, Madrid, Instituto Nebrija.

Bataillon, Marcel (1966): Erasmo y España, trad. A. Alatorre, México D.F., Fondo de Cultura Económica.

Belic, Oldrich (1969): "La estructura de El Coloquio de los perros", en Análisis estructural de textos hispanos, Madrid, Prensa Española, pp. 61-90.

Bierlaire, Franz (1977): Érasme et ses Colloques: le livre d'une vie, Ginebra, Librairie Droz.

Bizzarri, Hugo (2003): "Los refranes en Cervantes”, Boletín Hispánico Helvético, II, pp. 25-49.

Bizzarri, Hugo (2015): Diccionario de paremias cervantinas, Alcalá de Henares, Universidad de Alcalá.

Blanco Aguinaga, Carlos (1957): "Cervantes y la picaresca. Notas sobre dos tipos de realismo", Nueva Revista de Filología Hispánica, XI, no 3/4, pp. 313-342.

Blanco Aguinaga, Carlos (1997-1998): "Sobre Estilística y Formalismo ruso", Cauce, XX-XXI, $\mathrm{n}^{\mathrm{o}} 2$, pp. 29-44.

Bobes Naves, Carmen (2001): "Emilio Alarcos y la teoría de la literatura", en Homenaje al profesor Alarcos, Madrid-Oviedo, Gredos-Universidad de Oviedo, pp. 251-262.

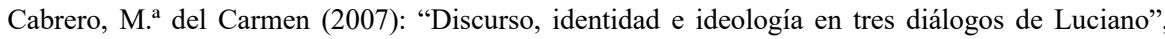
Nova Tellus, XXV, no 2, pp. 209-230.

Calero, Francisco (1994a): Los Diálogos de Juan Luis Vives, Valencia, Ayuntamiento.

Calero, Francisco (1994b): Linguae Latinae exercitatio / Ejercicios de lengua latina (1532) de Juan Luis Vives, trad. (junto con $\mathrm{M}^{\mathrm{a}}$ José Echarte), Valencia, Ayuntamiento.

Calero, Francisco (2004a): Juan Luis Vives, autor del "Diálogo de Mercurio y Carón", Valencia, Ayuntamiento.

Calero, Francisco (2004b): Juan Luis Vives, autor del "Diálogo de la lengua", Valencia, Ayuntamiento.

Calero, Francisco (2017): Estudio de autoría del "Persiles", "Philosophía antigua poética" y "Novelas ejemplares", Madrid, Dykinson.

Candelas Colodrón, Miguel Ángel (2003): "Modelos dispositivos del diálogo en el siglo XVI español”, Hesperia (Anuario de filología hispánica), VI, pp. 57-78.

Cantera Ortiz de Urbina, Jesús (2005): Diccionario Akal del Refranero Latino, Madrid, Akal.

Cantera Ortiz de Urbina, Jesús y Julia Sevilla Muñoz (2005): Refranes, otras paremias y fraseologismos en "Don Quijote de la Mancha", Vermont, Universidad de Vermont, 2005.

Carrasco, Félix (1983): "El coloquio de los perros /vs/ El asno de oro: concordancias temáticas y sistemáticas", Anales cervantinos, XXI, pp. 177-200.

Cervantes, Miguel de (2014) [2010]: Novelas Ejemplares (1613), II, ed. H. Sieber, Madrid, Cátedra.

Cervantes, Miguel de (2004, cfr. la última de 2015): Los trabajos de Persiles y Sigismunda. Historia septentrional (1617), ed. C. Romero Muñoz, Madrid, Cátedra. 
Colombi, María Cecilia (1989): Los refranes en el "Quijote": Texto y Contexto, Potomac, Scripta Humanistica.

Colón Domenech, Germà (2004): "Los Adagia de Erasmo en español (Lorenzo Palmireno, 1560) y en portugués (Jerónimo Cardoso, 1570)", Revista de Filología Española, LXXXIV, pp. 527. <https://doi.org/10.3989/rfe.2004.v84.i1.96>.

Donadi, Francesco (1989): "Sul meraviglioso in Luciano", en D. Lanza e O. Longo (eds.), Il meraviglioso e il verosimile tra antichità e Medioevo, Florencia, Olschki, pp. 195-209.

Donnely, Paul J. (1979): A Study of Spanish Translations of Erasmus's Colloquia (1525-1536), with Special Reference to the Translations of Alonso Ruiz de Virués, Oxford, Clarendon Press.

Erasmo de Rotterdam (2005): “Adagia" (1536), en Opera omnia, ed. M. Szymanski, Amsterdam, North-Holland Publishing Company.

Etymologicum Magnum (1848): ed. T. Gaisford, Oxford, Clarendon Press.

Flórez Flórez, Alfonso (2011): "La forma del diálogo y la forma de la filosofía en Platón", Franciscanum, LIII, $\mathrm{n}^{\circ}$ 156, pp. 369-398.

Focio (1982): Lexicon, ed. Ch. Theodoridis, Berlin-New York, De Gruyter.

Forcione, Alban K. (1984): Cervantes and the mistery of lawlessness: a study of "El casamiento engañoso" y "El coloquio de los perros", Princeton, Princeton University Press.

Gallardo, María Dolores (1974): "El simposio romano", Cuadernos de Filología Clásica, VII, pp. 91-143.

García Jurado, Francisco (2010): "La oralidad escrita del saber: Aulo Gelio y Michel de Montaigne", Studia Philologica Valentina, XII, no 9, pp. 71-83.

García Jurado, Francisco (2012): "Aulo Gelio y la literatura española del Siglo XVI: autor, texto, comentario y relectura moderna", Revista de literatura, LXXIV, n 147 , pp. 31-64.

García López, Jorge (ed.) (2015a): Novelas Ejemplares, Madrid, RAE.

García López, Jorge (2015b): Cervantes. La figura en el tapiz, Barcelona, Pasado y Presente.

García Romero, Fernando (2009): "Pervivencia de la tradición proverbial grecorromana", Proverbium, XXVI, pp. 119-150.

Gelio, Aulo (2009): Noches Áticas, trad. S. López Moreda, Madrid, Akal.

Gil Fernández, Luis (1997): Panorama social del humanismo español (1500-1800), Madrid, Editorial Tecnos.

Gómez, Jesús (1988): El diálogo en el Renacimiento español, Madrid, Cátedra.

Gómez, Jesús (2006): "La caracterización del personaje dialógico desde la ficción conversacional", en Consolación Baranda Leturio y Ana Vian Herrero (eds.), El personaje literario y su lengua en el siglo XVI, Madrid, Editorial Complutense, pp. 217-241.

Grigoriadu, Teodora (2009): "El Carón de Erasmo traducido por Juan de Aguilar Villaquirán: edición y estudio de la única traducción áurea del coloquio Charon de Erasmo de Rotterdam", Criticón, CVI, pp. 147-159. <https://doi.org/10.4000/criticon.13437>.

Herrero Llorente, Víctor José (1980): Diccionario de expresiones y frases latinas, Madrid, Gredos.

Hesiquio Alexandrinus (1953): Lexicon, ed. K. Latte, Copenhague, Ejnar Munksgaard editore.

Hjelmslev, Louis (1972): Ensayos Lingüísticos, Madrid, Gredos.

Joly, Monique (1984): "Le discours métaparémique dans Don Quijotte", en F. Suard y C. Buridant (eds.), Richesse du proverbe, I, Lille, Universidad de Lille, pp. 245-260.

Joly, Monique (1991): "La paremiología cervantina: una reconsideración del problema", Ínsula, DXXXVIII, pp. 23-24.

Lelli, Emanuele (ed.) (2006): I proverbi greci. Le raccolte di Zenobio e Diogeniano, Soveria Mannelli, Rubettino.

León, Luis de (1990): "De los nombres de Cristo", en Obras Completas, ed. A. Sánchez Zamarreño, Madrid, Espasa Calpe. 
Leutsch, Ernst von y Schneidewin, Friedrich Wilhelm (1965): Corpus Paroemiographorum Graecorum $(C P G)$, Hildesheim, Georg Olms.

Mañero Lozano, David (2004): "Diálogo y picaresca en El Coloquio de los perros", Bulletin Hispanique, CVI, ${ }^{\circ}$ 2, pp. 497-520. <https://doi.org/10.3406/hispa.2004.5200>.

Miranda, Marta Isabel (1985): "Cipión: su carácter y sus funciones en El coloquio de los perros", Anales Cervantinos, XXIII, pp. 195-200.

Murillo, Luis Andrés (1961): "Cervantes' Coloquio de los perros. A novel-dialogue", Modern Philology, LVIII, pp. 174-185. <https://doi.org/10.1086/389388>.

O'Kane, Eleanor S. (1959): Refranes y frases proverbiales españolas de la Edad Media, Madrid, BRAE (Anejo II).

Pérez Jiménez, Aurelio (2014): "Plutarco y la iconografía monetaria antigua", en Carlos Alcalde Martín y Luísa de Nazaré Ferreira (eds.), O sábio e a imagen. Estudos sobre Plutarco e a arte, Coimbra, Universidad de Coimbra.

Pozuelo Yvancos, José M. ${ }^{\text {a }}$ (1978): "El pacto narrativo: semiología del receptor inmanente en $E l$ Coloquio de los perros", Anales Cervantinos, XVII, pp. 147-166.

Rey Hazas, Antonio (1983): "Género y estructura de El coloquio de los perros o cómo se hace una novela", en José Jesús de Bustos Tovar (coord.), Lenguaje, ideología y organización textual en las "Novelas ejemplares" (Actas del Coloquio, Facultad de Filología de la Universidad Complutense, mayo de 1982), Madrid, Universidad Complutense de Madrid-Universidad de Toulouse-Le Mirail.

Rey Quesada, Santiago del (2012): El discurso dialógico en el castellano del siglo XVI: las traducciones de los Coloquios de Erasmo, tesis doctoral, Sevilla, Universidad de Sevilla.

Rey Quesada, Santiago del (2013): "Reflexiones sobre la traducción en los traductores de los Coloquios de Erasmo", 1611. Revista de Historia de la Traducción, VII.

Sáez, Adrián J. (2014): "Más sobre Cervantes, Plutarco y los cínicos: una anécdota de Alcibíades y El Coloquio de los perros", Anales Cervantinos, XLVI, pp. 149-160. <https://doi.org/ 10.3989/anacervantinos.2014.009>.

Sánchez Doncel, Gregorio (1997): Diccionario de Latinismos y Frases Latinas, Madrid, Noesis.

Saussure, Ferdinand de (1945): Curso de Lingüística General, trad. y pról. A. Alonso, Buenos Aires, Losada.

Schottus, André (1612): Paroimiai Hellçnikai. Adagia sive proverbia Graecorum ex Zenobio seu Zenodoto, Diogeniano \& Suidae collectaneis, Amberes, Ex Officina Plantiniana (apud viduam $\&$ filios Ioannis Moreti).

Schwartz, Lía (1992): "El diálogo en la cultura áurea: de los textos al género", Ínsula, DXLII, pp. 1-28.

Serrano Cueto, Antonio (2002): "El erasmismo de Polidoro Virgilio o el adagio crítico", Calamus Renascens, III, pp. 273-293.

Sevilla Arroyo, Florencio (1992): "Los Diálogos narrativos: entre novela y coloquio", Ínsula, DXLII, pp. 15-19.

Suidae Lexicon (1971): ed. A. Adler, Pars I A-Ã, Stuttgart, Teubner, p. $488\left(\mathrm{n}^{\circ} 460\right)$.

Szlezák, Thomas A. (2009): "Reflejo del discurso vivo. ¿Qué es y qué pretende un diálogo platónico?", Areté, XXI, no 1, pp. 87-110.

Torquemada, Antonio (1994): "Jardín de flores curiosas", en Obras completas, I, ed. Lina Rodríguez Cacho, Madrid, Turner.

Valdés, Alfonso de (1999): Diálogo de Mercurio y Carón, ed. Rosa Navarro, Madrid. Cátedra.

Valdés, Juan de (1982): Diálogo de la lengua, ed. C. Barbolani, Madrid, Cátedra.

Vega, Pilar M. (1990): "Consideraciones paremiológicas cervantinas", en Actas del primer coloquio internacional de la Asociación de Cervantistas, Barcelona, Anthropos, pp. 315-332.

Vilanova, Antonio (1989): Erasmo y Cervantes, Barcelona, Lumen.

Villanueva Márquez, Darío (2001): "Emilio Alarcos, crítico literario", en Homenaje al Prof. Alarcos, Madrid/Oviedo, Gredos/Universidad de Oviedo, pp. 187-206. 
Villalón, Cristóbal de (1982): El Crotalón de Cristóforo Gnofoso, ed. Asunción Rallo, Madrid, Cátedra.

Virgilio, Polidoro (2007): Libro de los Proverbios (1498), trad. A. Serrano Cueto, Madrid, Akal. Virgilio Marón, Publio (1969): Opera omnia: Aeneidos, ed. crítica R. Mynors, Oxford, Clarendon Press.

Virgilio Marón, Publio (2000): La Eneida, traducida por G. Hernández de Velasco (1555), ed. V. Bejarano, Barcelona, Planeta.

Virgilio Marón, Publio (2008): La Eneida, trad. R. Bonifaz Nuño, México, UNAM.

Walther, Hans (1982-1986): Proverbia sententiaque latinitatis medii ac recentiores Aevi, II/7, Göttingen, Vandenboeck \& Ruprecht.

Fecha de recepción: 15 de agosto de 2018

Fecha de aceptación: 24 de octubre de 2018 